\title{
Comparação dos sistemas de cultivo nativo e adensado de erva mate, Ilex paraguariensis St. Hil., quanto à ocorrência e flutuação populacional de insetos ${ }^{1}$
}

\author{
Larissa R. Borges ${ }^{2}$ \\ Sonia Maria Noemberg Lázzari ${ }^{2}$ \\ Flávio Antonio Lázzari ${ }^{3}$
}

\begin{abstract}
Occurrence and population fluctuation of insects on native and dense cropping systems of maté, Ilex paraguariensis St. Hil. This research was carried out in order to compare the occurrence of insects in two maté cultivation systems, native and high tree density. It was performed from August/2000 to September/2001, in a private property in São Mateus do Sul county, in Paraná State, Brazil. Visual inspections of trees and light traps were used to evaluate insect populations in both areas. For Hedypathes betulinus (Klug) (Coleoptera, Cerambycidae), only six adults were observed in the dense area. Based on presence of sawdust at the basis of the trunk, it was obtained that the number of attacked trees did not surpass $11 \%$ in either area. For Gyropsylla spegazziniana (Lizer y Trelles) (Hemiptera, Psyllidae), the number of galls per tree was counted and it was observed that the population peak occurred from November to January. For Hylesia spp. (Lepidoptera, Saturniidae) and Thelosia camina Schaus (Lepidoptera, Eupterotidae), the presence of caterpillars on the trees was noticed from September to February, with the population peak in November and December. Adults of Hylesia spp. were more numerous in February and March. Two species that were not previously recorded for Brazil on maté were identified: Hylesia paulex Dognin (83\%) and Hylesia remex Dyer (17\%), collected with light traps. The maté caterpillar, T. camina was not collected with these traps. Nymphs and adults of Ceroplastes grandis Hempel (Hemiptera, Coccidae) were observed along the year on the branches, with population peak between April and June for the nymphs and from September to November for the adults. It should be considered that despite higher insect incidence in the dense area compared to the native area, the first presents higher yield, and that with a good pest management program the insect problems can be minimized.
\end{abstract}

KEYwORDs. Damages; insect fluctuation; maté crop; insect survey.

\section{INTRODUÇÃO}

A erva-mate, Ilex paraguariensis St. Hil. (Aquifoliaceae), é uma espécie que cresce na Floresta Ombrófila Mista, um ecossistema associado à Mata Atlântica, onde pode atingir densidades de centenas de árvores/ha (MIRANDA \& URBAN 1998). Todavia, quando cultivada em locais abertos (sem cobertura florestal), esta espécie fica sujeita a estresses fisiológicos que a predispõe ao aparecimento de pragas e doenças (CARPANEZZI 1995).

Nos ambientes naturais, ocorre uma diversidade de plantas que garantem a existência de uma gama de artrópodes associados. Entretanto, uma simplificação desses ecossistemas tende a gerar impactos que favorecem algumas espécies de insetos fitófagos em detrimento de seus inimigos naturais (IEDE 1985; DiAZ 1997).

IEDE \& MACHADO (1989) citaram a ocorrência de 86 espécies de insetos alimentando-se de diferentes partes da erveira, porém, poucas podem ser consideradas pragas, uma vez que a maioria ocorre esporadicamente em baixos níveis populacionais, não causando danos econômicos significativos. As espécies comumente citadas como pragas de I. paraguariensis são: Hedypathes betulinus (Klug, 1825) (Coleoptera, Cerambycidae), popularmente conhecido como broca-da-erva-mate ou corintiano; Gyropsylla spegazziniana (Lizer y Trelles, 1919) (Hemiptera, Psyllidae), ampola-da-erva-mate; Thelosia camina Schaus, 1920 (Lepidoptera, Eupterotidae), a lagarta-da-ervamate; Hylesia spp. (Lepidoptera, Saturniidae) que compreende

1. Contribuição n 1370 do Departamento de Zoologia, Universidade Federal do Paraná.

2. Departamento de Zoologia, Universidade Federal do Paraná. Caixa Postal 19020, 81531-980 Curitiba - PR, Brasil. Bolsistas do CNPq. Endereço eletrônico: lazzari@ufpr.br

3. Pós-graduação em Entomologia, Universidade Federal do Paraná. Endereço eletrônico: lazzari@brturbo.com 
diversas espécies conhecidas como lagartas-do-cartucho, sendo registradas as espécies Hylesia sorana Schaus, 1927 e Hylesia fulviventris (Berg, 1883), no Brasil e Hylesia nigricans (Berg, 1876), na Argentina (SILva et al. 1968; DiAz 1997); Ceroplastes grandis Hempel, 1900 (Hemiptera, Coccidae) conhecida como cochonilha-de-cera (Figs. 1 a 5) (PEDrosAMacedo 1993; Penteado 1995; Iede et al. 2000).

Apesar dos ácaros causarem grandes danos à cultura da erva-mate, estes não foram tratados nesta pesquisa. As espécies citadas para a erva-mate são: Dichopelmus notus Keifer, 1959 (Acari, Eriophyidae), o ácaro do bronzeado; Polyphagotarsonemus latus (Banks, 1904) (Acari, Tarsonemidae), o ácaro branco; e Oligonychus yothersi (Mc Gregor, 1914) (Acari, Tetranychidae) (Alves et al. 2000; Penteado et al. 2000).

Diante desse panorama, torna-se importante a adoção de medidas que assegurem a preservação e aumento da cobertura florestal, em algumas áreas, visando a melhoria na qualidade e produtividade da erva-mate, atendendo às atuais exigências do mercado. Portanto, o objetivo desta pesquisa foi comparar a ocorrência e flutuação de insetos em sistemas de cultivo nativo e adensado, a fim de se determinar o sistema de cultivo mais adequado em termos ecológicos, sem comprometer a rentabilidade.

\section{MATERIAL E MÉTODOS}

Os experimentos foram realizados em uma propriedade situada em Estiva, município de São Mateus do Sul-PR, no segundo planalto paranaense, altitude aproximada de $800 \mathrm{~m}$, $25^{\circ} 52^{\prime}$ de latitude Sul e 50 23 ' de longitude Oeste. O clima da região, segundo a classificação de Köppen, é do tipo $\mathrm{Cfb}$, subtropical úmido sem estação seca, precipitação média anual entre 1400 e $1500 \mathrm{~mm}$, com temperatura média do mês mais quente inferior a $22^{\circ} \mathrm{C}$ e a média do mês mais frio superior a $10^{\circ} \mathrm{C}$, com mais de cinco geadas por ano. O tipo de solo é uma associação de latossolo vermelho-escuro álico (70\%) + terra bruna estruturada (30\%). A vegetação remanescente é do tipo Floresta Subtropical Perenifólia (Mata de Araucária), formada por árvores de médio e grande porte, com pinheiros (Instituto Brasileiro de Desenvolvimento Florestal 1984; LARACH et al. 1984).

Nessa propriedade, com 68 ha, foram delimitadas duas parcelas próximas de 1 ha para cada sistema de plantio de ervamate, nativo e adensado.

O erval nativo é caracterizado por árvores de erva-mate nativas, cuja idade não é possível precisar, e sem espaçamento definido entre elas. Outra característica é o sombreamento ou nível de radiação solar parcial, devido ao tipo de cobertura por outras espécies arbóreas (MAZUCHOwSKI 2000). Nesta área experimental havia aproximadamente 171 árvores de $I$. paraguariensis e 748 de outras espécies, sendo as mais representativas: Araucaria angustifolia, pinheiro-do-Paraná (Araucariaceae); Ocotea puberula, canela-guaicá (Lauraceae) e Blepharocalyx solicifolius, murteira (Myrtaceae).

O erval adensado é um erval inicialmente nativo, mas que, após a retirada da vegetação de pequeno porte e sem valor econômico, é acrescido de mudas de erva-mate (ANDRADE 1999), portanto, o espaçamento também não é definido. $\mathrm{O}$ plantio para adensamento nesta área experimental foi realizado em 1996 com mudas provenientes da região. $\mathrm{Na}$ área de erval adensado com 563 erveiras, o número de $I$. paraguariensis nativa era aproximadamente 1/4 do total, com 226 árvores de outras espécies, sendo que $A$. angustifolia era a mais representativa.

Para a determinação da ocorrência e flutuação populacional dos insetos, foram realizadas 28 coletas, com freqüência quinzenal na área demarcada de erval nativo e adensado, durante o período de agosto/2000 a setembro/2001. As técnicas utilizadas foram a inspeção visual das plantas e armadilhas luminosas.

As inspeções visuais, mediante a contagem de insetos em ramos infestados, sem remoção dos insetos, foram feitas em dez árvores de cada um dos sistemas de plantio. Entretanto, a partir de maio/2001 em função da poda, a inspeção passou a ser feita em sete árvores podadas e sete árvores não podadas em cada um dos sistemas de plantio. A avaliação da presença de $H$. betulinus foi complementada com o levantamento dos danos baseado na presença de árvores atacadas, isto é, que apresentavam serragem lançada para fora pelos orifícios na base do tronco, em julho/2001 e em janeiro/2002.

Para a coleta de adultos de lepidópteros noturnos, foram instaladas três armadilhas, uma em cada área de plantio e uma na área de transição, com aproximadamente 1,5 m de altura. A metodologia de coleta utilizada foi a de MARINONI \& DUTRA (1991), com armadilhas do tipo ESALQ - modificada, com lâmpada mista de mercúrio de $160 \mathrm{~W}$ - $220 \mathrm{~V}$ (Fig. 6). Para a recepção dos exemplares colocou-se na extremidade do funil um frasco de polietileno (capacidade para $20 \mathrm{~L}$ ), contendo $5 \mathrm{~L}$ de álcool a 70\%. Estas armadilhas foram ligadas uma vez ao mês, na fase de lua nova, das 6 horas da tarde às 6 horas da manhã do dia seguinte (com um atraso de uma hora no horário de verão).

Os exemplares coletados foram transferidos para frascos de $1000 \mathrm{~mL}$ e transportados para o Departamento de Zoologia do Setor de Ciências Biológicas da UFPR, para a triagem e montagem do material. Dados de precipitação pluviométrica e temperatura foram obtidos da Estação da Petrobrás em São Mateus do Sul - PR. Quando aplicável, os dois tratamentos (nativo e adensado) foram comparados pelo Teste $\mathrm{t}$ e/ou correlacionados com a média mensal das temperaturas e total mensal da precipitação pluviométrica.

\section{RESULTADOSEDISCUSSÃO}

\section{Inspeção visual das erveiras}

Hedypathes betulinus. As inspeções foram realizadas durante o período de agosto/2000 a setembro/2001, entretanto os adultos de $H$. betulinus foram registrados apenas entre os meses de janeiro e março/2001. Os seis indivíduos observados, quatro fêmeas e dois machos, estavam no erval adensado, não tendo sido registrados adultos em erval nativo. 

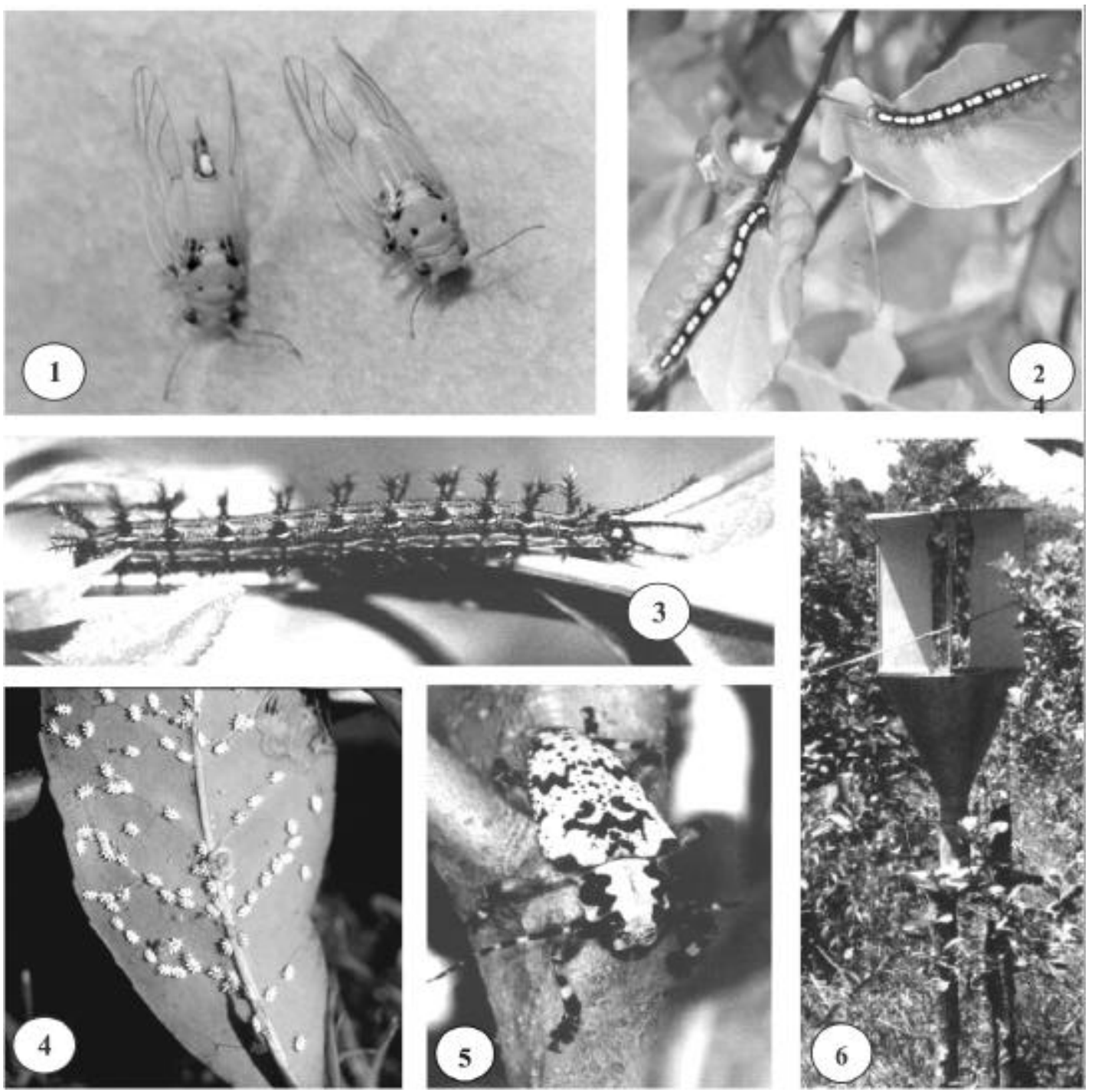

Figs. 1-6. Principais pragas da erva-mate: 1, Gyropsylla spegazziniana (fêmea, à esquerda e macho, à direita); 2, Thelosia camina; 3, Hylesia sp.; 4 , Ceroplastes grandis; 5, Hedypathes betulinus; 6, Armadilha luminosa tipo ESALQ-modificada. (Fotos: 1-M. S. Pereira Leite; 2-Dalva Santana).

Devido ao baixo número de adultos observados, não foi possível estimar quando ocorre o pico populacional dessa espécie mas, segundo SOAREs (1998), em estudo realizado em Ivaí-PR, os adultos estariam presentes no erval durante praticamente todo o ano, com o pico entre os meses de fevereiro e março. O número de adultos de H. betulinus observados nas coletas não expressa o tamanho da população, pois são de difícil visualização em meio à vegetação rasteira presente nas duas áreas estudadas.

Amostragens dos danos causados pelas larvas de $H$. betulinus (Tabela I) revelaram que o erval mais infestado em julho foi o nativo (10,6\% contra 7,8\% no adensado), porém, em janeiro ocorreu o contrário $(9,5 \%$ contra $10,9 \%)$; entretanto, não houve diferença significativa (intervalo de confiança $>95 \%$ ) desses danos nas duas áreas.

A porcentagem de árvores atacadas (menor que 11\%) foi muito inferior aos $91 \%$ encontrado por SOARES (1998), em erval estreme (monocultura). Segundo CARPANEZZI (1995), populações elevadas de $H$. betulinus são indicadoras do desequilíbrio entre o ambiente natural e de monocultura da erva-mate.

Tabela I. Número de árvores de erva-mate, Ilex paraguariensis, com e sem sintomas de ataque de Hedypathes betulinus (presença de serragem na base do tronco), em sistemas de cultivo nativo e adensado em São Mateus do Sul, PR.

\begin{tabular}{lcclcc}
\hline & \multicolumn{2}{c}{ Erval Nativo } & & \multicolumn{2}{c}{ Erval Adensado } \\
\cline { 2 - 3 } \cline { 6 - 6 } $\begin{array}{l}\text { Data de } \\
\text { coleta }\end{array}$ & $\begin{array}{c}\text { Prença } \\
\mathrm{n}^{\circ}(\%)\end{array}$ & $\begin{array}{c}\text { Ausência } \\
\mathrm{n}^{\circ}(\%)\end{array}$ & & $\begin{array}{c}\text { Presença } \\
\mathrm{n}^{\circ}(\%)\end{array}$ & $\begin{array}{c}\text { Ausência } \\
\mathrm{n}^{\circ}(\%)\end{array}$ \\
\hline Julho/2001 & $15(10,6)$ & $126(89,4)$ & & $43(7,8)$ & $509(92,2)$ \\
Janeiro/2002 & $6(9,5)$ & $57(90,5)$ & & $42(10,9)$ & $384(89,1)$ \\
\hline
\end{tabular}


No erval adensado, observou-se que a grande maioria das árvores atacadas foram as nativas, apesar dessas representarem apenas $1 / 4$ do número total de erveiras. Observações realizadas por SOARES (1998) indicam que as árvores mais atacadas são as com mais de cinco anos de idade. No erval adensado, as árvores formam plantadas em 1996 e apresentavam um crescimento mais lento por receber menor insolação e com menor diâmetro o que poderia condicionar a baixa ocorrência de H. betulinus.

No erval nativo, as árvores mais atacadas por $H$. betulinus estavam localizadas em uma clareira no final da área do experimento, indicando que o ataque desses insetos pode ocorrer, preferencialmente, em locais mais abertos.

Gyropsylla spegazziniana. A maior ocorrência da ampolada-erva-mate em erval adensado foi observada no período de novembro/2000 a fevereiro/2001 e, praticamente, no mesmo período para o erval nativo, onde observou-se um pequeno decréscimo no mês de janeiro (Fig. 7).

A ocorrência das ampolas nos dois tratamentos (nativo e adensado) foi comparada pelo Teste t, e correlacionada com a média mensal das temperaturas e com a precipitação pluviométrica mensal. Observou-se que o erval nativo apresentou diferença altamente significativa em relação ao erval adensado ( $p>0,0004)$. As análises de correlação entre temperatura e sistema de cultivo apresentaram $r=0,62$ para nativo e $r=0,82$ para adensado, o que indicou a existência de associação entre temperatura e número de ampolas. O mesmo não ocorreu com a pluviosidade que apresentou $\mathrm{r}=0,026 \mathrm{e} \mathrm{r}=$ 0,25 para nativo e adensado, respectivamente. Apesar do resultado estatístico não indicar correlação entre pluviosidade e número de ampolas, observou-se acentuada diminuição destas após chuvas pesadas, concordando com IEDE et al. (2000), os quais constataram que elevadas precipitações pluviométricas parecem reduzir a população da praga por causarem a queda das ampolas.

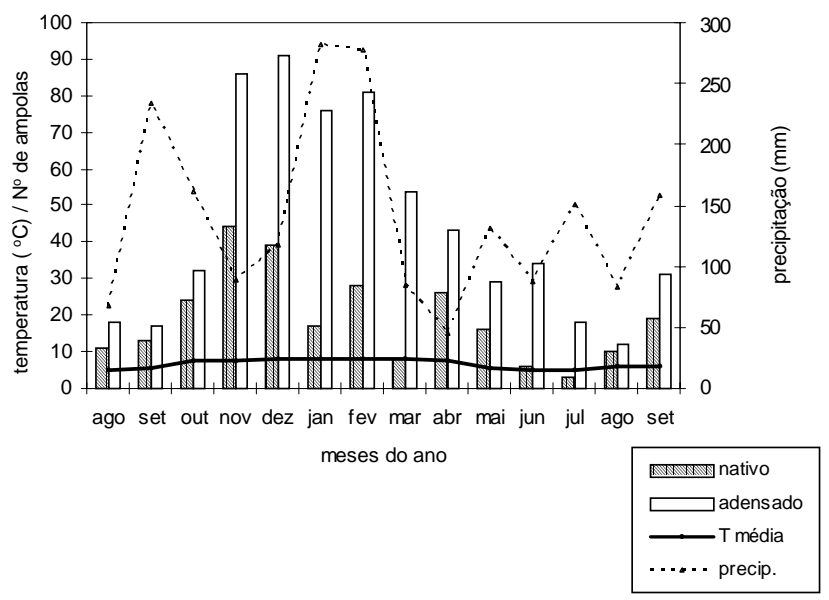

Fig. 7. Número de ampolas de Gyropsylla spegazziniana em erva-mate, Ilex paraguariensis, em sistemas de cultivo nativo e adensado, correlacionado com temperatura e precipitação pluviométrica, em São Mateus do Sul, PR, 2000-2001. A partir de Maio/2001 a inspeção passou a ser feita em 14 árvores, em função da poda.
Thelosia camina. As lagartas foram observadas em erval adensado a partir de setembro/2000 até fevereiro/2001, com pico populacional em dezembro (Fig. 8), não sendo observadas nos outros meses. Em erval nativo, as lagartas foram observadas apenas nos meses de dezembro/2000 e janeiro/2001.

Houve maior ocorrência desta espécie em erval adensado, embora o número de lagartas observadas em ambos fosse baixa. Em ervais estremes, ou seja, em sistema de monocultura, localizados próximos ao experimento, as populações de $T$. camina foram bastante elevadas em toda a área de cultivo.

O período de ocorrência das lagartas está de acordo com o observado por IEDE et al. (2000); entretanto, KoBER \& VARGAS (1960) observaram lagartas nas plantas até, no máximo, em dezembro.

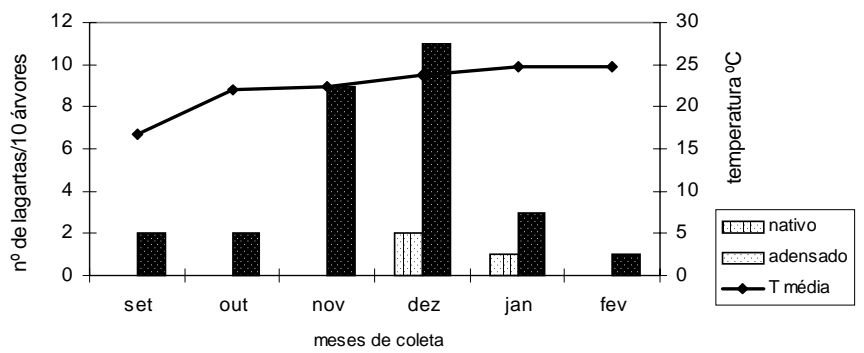

Fig. 8. Ocorrência de lagartas de Thelosia camina em 10 árvores de erva-mate, Ilex paraguariensis, em sistemas de cultivo nativo e adensado, em São Mateus do Sul, PR, 2000-2001.

\section{Hylesia spp.}

Os dados referentes à flutuação das espécies de Hylesia foram baseados na presença de lagartas de $5^{\circ}$ ínstar (Fig. 9). Segundo Oliveira \& Urban (1979), nesta fase as lagartas começam a tecer fios de seda entre os galhos da planta hospedeira.

O período de ocorrência foi de outubro a início de dezembro, quando estas se encontravam nos cartuchos de seda, onde se contou mais de uma centena de indivíduos. A partir da segunda quinzena de dezembro, as lagartas deixaram de apresentar hábito gregário e foram encontradas isoladas. Este comportamento também foi observado por Oliveira \& URBAn (1979) e IEdE \& MACHADO (1989).
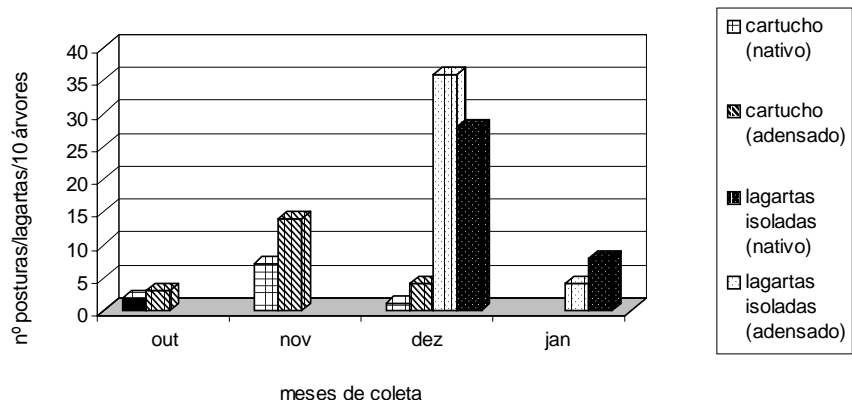

Fig. 9. Número de lagartas de Hylesia spp. em 10 árvores de erva-mate, Ilex paraguariensis, em sistemas de cultivo nativo e adensado, em São Mateus do Sul, PR, 2000-2001. 
Ceroplastes grandis. A ocorrência da cochonilha-de-cera foi predominante em erval adensado durante todo o período de coleta (Figs. 10a e 10b). As ninfas predominaram entre abril e junho, concordando com as observações de Iede (comunicação pessoal). Os adultos foram mais numerosos nos meses de setembro a novembro, decrescendo gradativamente.

A proporção de árvores atacadas por adultos de $C$. grandis em ambas as áreas foi baixa, ocorrendo geralmente em reboleira, semelhante às observações de IEdE \& Machado (1989). Verificou-se também um alto índice populacional de ninfas em uma única árvore, geralmente, nos ramos mais finos e nas folhas.
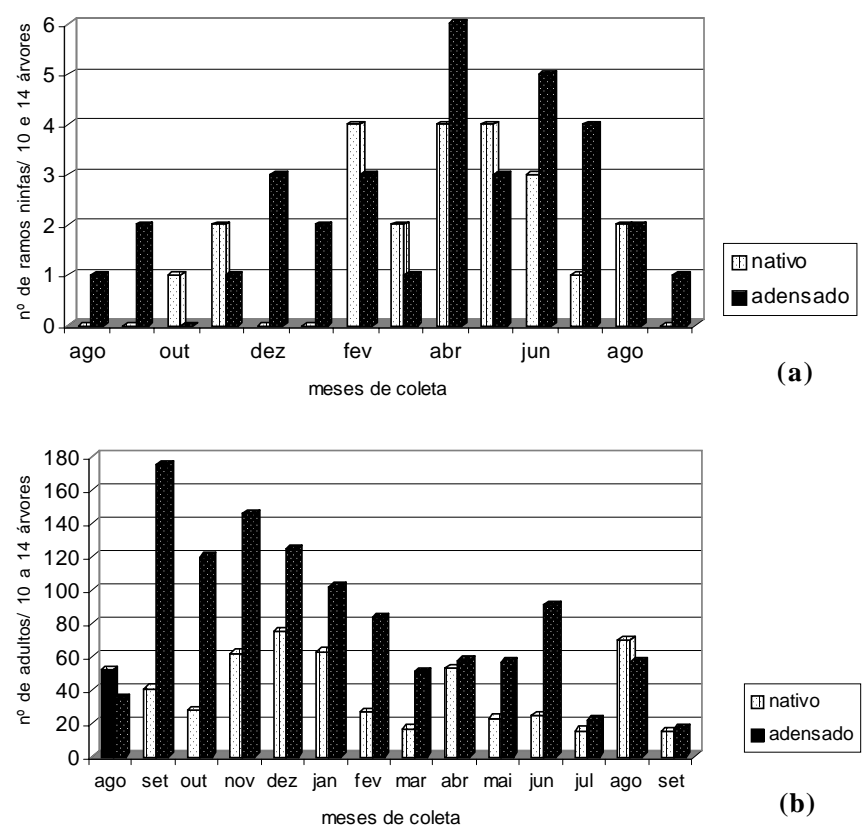

Fig. 10. Número de ramos infestados com ninfas (a) e número de adultos (b) de Ceroplastes grandis em erva-mate, Ilex paraguariensis, em sistemas de cultivo nativo e adensado, em São Mateus do Sul, PR, 2000-2001. A partir de Maio/2001 a inspeção passou a ser feita em 14 árvores, em função da poda.

\section{Armadilhas luminosas.}

A ocorrência dos adultos de Hylesia foi, praticamente, durante todo o período de coleta, com exceção dos meses de junho e julho/2001. O pico populacional ocorreu nos meses de fevereiro e março/2001 (Fig. 11). O número elevado de espécimens deste gênero nas armadilhas pode ser devido à riqueza de espécies arbóreas nas áreas de estudo, inclusive de outras Aquifoliaceae, que podem servir como hospedeiras de espécies de Hylesia.

Foram coletadas as espécies Hylesia paulex Dognin (83\%) e Hylesia remex Dyer, 1922 (17\%), sendo este o primeiro registro das mesmas em erva-mate no Brasil. A espécie $H$. paulex é citada por SiLva et al. (1968) atacando ameixeira no Estado de Minas Gerais. É possível que haja outras espécies, pois, além de haver muitos exemplares danificados pelo álcool, dificultando a identificação, o grupo é taxonomicamente complexo.

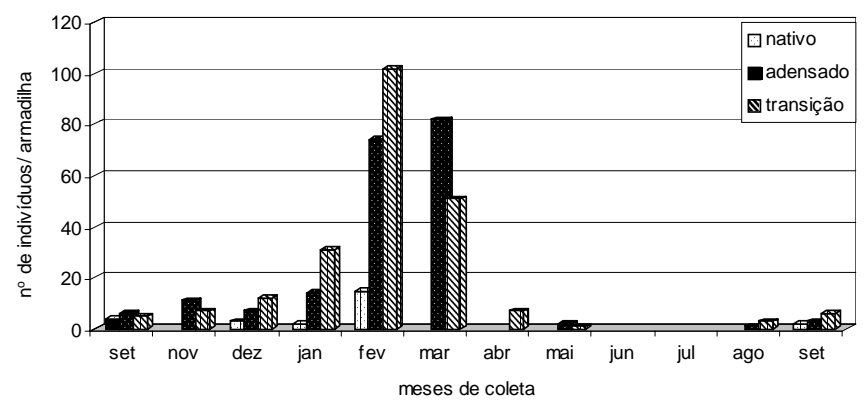

Fig. 11. Número de adultos de Hylesia spp. em erva-mate, Ilex paraguariensis, coletados com armadilha luminosa, em São Mateus do Sul, PR, 2000-2001.

Não foram coletados adultos de T. camina nas armadilhas luminosas, talvez devido à metodologia de coleta.

Comparando-se os resultados das coletas nos dois sistemas estudados, observa-se que o erval nativo apresenta menor incidência de pragas que o erval adensado e que a ocorrência das espécies de insetos aumenta no período de primaveraverão. Contudo, é importante considerar que a rentabilidade do erval nativo é mais baixa que a do erval adensado e, segundo a literatura, a monocultura apresenta um rendimento maior, mas com o problema de pragas grandemente agravado. Desta forma, a recomendação seria de se optar pelo sistema de cultivo adensado, adotando-se estratégias integradas de manejo, inclusive com o estabelecimento dos níveis econômicos de danos de cada espécie, para contornar o problema das pragas no sistema adensado. Assim, estariam sendo atendidos os requisitos de produção de escala, rentabilidade econômica e a manutenção do equilíbrio ecológico desse agroecossistema.

Agradecimentos. Ao Dr. Claude Lemaire, do Muséum National d' Histoire Naturelle, Paris, França, pela identificação das espécies de Hylesia; à indústria BALDO na pessoa de Leandro B. Gheno; aos pesquisadores da EMBRAPA Florestas pelo auxílio técnico e à família Zampier pela amizade e colaboração nas coletas.

\section{REFERÊNCIAS}

Alves, L. F. A.; D. L. Q. Santana; P. M. O. J. Neves \& R. C. Oliveira. 2000. Ácaros fitófagos da erva-mate: situação atual e perspectivas de controle, p. 39-42. In: II Congresso Sul-Americano da ErvaMate e III Reunião Técnica da Erva-mate. Encantado, Ed. dos Organizadores.

Andrade, F. M. 1999. Exploração e utilização do recurso Ilex paraguariensis St. Hil., erva-mate, seus impactos sócio-econômicos atuais e potencialidades de manejo sustentável, p. 24-33. In: I Seminário Nacional de Recursos Florestais da Mata Atlântica. São Paulo, Ed. dos Organizadores.

Carpanezzi, A. A. 1995. Cultura do mate no Brasil: conflitos e lacunas, p. 43-47. In: H. Winge; A. G. Ferreira; J. E. A. Mariath \& L. C. TARAsconi (eds.). Erva-mate: Biologia e Cultura no Cone Sul. Porto Alegre, Ed. Universidade.

Diaz, C. I. F. 1997. Perspectivas del manejo integrado de plagas em yerba mate, p. 371-390. In: I Congresso Sul-Americano da ErvaMate e II Reunião Técnica do Cone Sul sobre a Cultura da Erva-mate. Curitiba, Ed. dos Organizadores. 
IEDE, E. T. 1985. Considerações sobre a entomofauna da erva-mate (Ilex paraguariensis St. Hil.), p. 111-118. In: Seminário sobre atualidades e perspectivas florestais - Silvicultura da ervamate (Ilex paraguariensis St. Hil.). EMBRAPA/CNPF.

Iede, E. T. \& D. C. Machado. 1989. Pragas da Erva Mate (Ilex paraguariensis St. Hil.) e seu controle. Colombo, EMBRAPA/ CNPF, Boletim de Pesquisa Florestal 18/19: 51-60.

Iede, E. T.; C. M. S. Soares; A. Grigoletti Júnior \& C. G. Auer. 2000. Manual de identificação de pragas e doenças da erva mate (Ilex paraguariensis St. Hil.). Colombo, Embrapa/CNPF, 24 p.

Instituto Brasileiro Do Desenvolvimento Florestal. 1984. Inventário Florestal Nacional. Brasília, IBDF, 309 p.

Kober, E. \& E. VArgas. 1960. Biologia e controle da "lagarta-da-ervamate" (Thelosia camina Schaus, 1920) (Lepidoptera: Eupterotidae). Revista da Escola de Agronomia e Veterinária 3: 7-35.

Larach, J. O.; A. Cardoso; A. P. CARvalho; D. P. Huchmüler; P. J. Fasolo \& M. J. RAUEN. 1984. Levantamento e reconhecimento dos solos do estado do Paraná. Curitiba, Embrapa/ Suldesul/ Iapar, 791 p.

Marinoni, R. C. \& R. C. Dutra. 1991. Levantamento da Fauna Entomológica no Estado do Paraná. Revista Brasileira de Zoologia 8: 31-73.

MAZUChOwsKi, J. Z. 2000. Alternativas para o incremento da produtividade em ervais nativos, p. 6-9. In: II Congresso Sul-Americano da Erva-Mate e III Reunião Técnica da Erva-mate. Encantado, Ed. dos Organizadores.
Miranda, N. \& T. URban. 1998. Engenhos e barbaquás. Curitiba, Ed. Posigraf, $120 \mathrm{p}$

Oliveira, B. L. \& D. Urban. 1979. Notas sobre a biologia de Hylesia corevina (Shaus, 1900) (Lepidoptera: Hemileucidae). Dusenia 11: 103-108.

Pedrosa-Macedo, J. H. 1993. Manual de Pragas Florestais-Pragas Florestais do Sul do Brasil. Curitiba, IPEF/SIF, 112 p.

Penteado, S. R. C. 1995. Principais pragas da erva-mate e medidas alternativas para o seu controle, p. 109-120. In: H. Winge; A. G. Ferreira; J. E. A. Mariath \& L. C. Tarasconi (eds.). Erva-mate: Biologia e Cultura no Cone Sul. Porto Alegre, Ed. Universidade.

Penteado, S. R. C.; E. T. Iede \& M. S. P. Leite. 2000. Pragas da erva-mate: perspectivas de controle, p. 27-38. In: II Congresso SulAmericano da Erva-Mate e III Reunião Técnica da Erva-mate. Encantado, Ed. dos Organizadores.

Silva, A. G.; C. R. GonÇalves; D. M. Galvão; A. J. L. GonÇalves; J. Gomes; M. N. Silva \& L. Simoni. 1968. Quarto catálogo dos insetos que vivem nas plantas do Brasil - seus parasitos e predadores. Rio de Janeiro, Ministério da Agricultura, 622 p.

Soares, C. M. S. 1998. Flutuação populacional, aspectos comportamentais e levantamento de inimigos naturais de Hedypathes betulinus (Klug, 1825) (Coleoptera: Cerambycidae) em um povoamento puro de erva-mate (Ilex paraguariensis $\mathrm{St}$. Hil.). Tese de Doutorado. Curitiba, Universidade Federal do Paraná, $73 \mathrm{p}$ 